BMJ Open Diabetes Research \& Care

\title{
Consumption of fat-free dairy products is not associated with a lower risk of maternofetal adverse events
}

Carla Assaf-Balut (1D ,1,2 Nuria Garcia de la Torre, ${ }^{1,3}$ Elena Bordiu, ${ }^{1,2}$ Laura del Valle, ${ }^{1}$ Johanna Valerio, ${ }^{1,2}$ Inés Jimenez, ${ }^{1}$ Alejandra Duran, ${ }^{1}$ Manuel Fuentes, ${ }^{4}$ Miguel Angel Herraiz, ${ }^{5}$ Nuria Izquierdo, ${ }^{5}$ Isabelle Runkle, ${ }^{1}$ Paz de Miguel, ${ }^{1,2}$ Cristina Familiar, ${ }^{1}$ Maria Carmen Montañez, ${ }^{1}$ Ana Barabash, ${ }^{1,3}$ Veronica Melero, ${ }^{6}$ Martín Cuesta, ${ }^{1,3}$ Miguel Rubio, ${ }^{1}$ Alfonso Luis Calle-Pascual (1) ${ }^{3,6}$

To cite: Assaf-Balut $\mathrm{C}$, Garcia de la Torre N, Bordiu E, et al. Consumption of fatfree dairy products is not associated with a lower risk of maternofetal adverse events. BMJ Open Diab Res Care 2020;8:e001145. doi:10.1136/ bmjdrc-2019-001145

- Additional material is published online only. To view, please visit the journal online (http://dx.doi.org/10.1136/ bmjdrc-2019-001145).

CA-B and NGdIT contributed equally.

Received 24 December 2019 Revised 31 January 2020 Accepted 9 March 2020
Check for updates

(c) Author(s) (or their employer(s)) 2020. Re-use permitted under CC BY-NC. No commercial re-use. See rights and permissions. Published by BMJ.

For numbered affiliations see end of article.

Correspondence to Dr Alfonso Luis Calle-Pascual; acallepascual@hotmail.com

\section{ABSTRACT}

Background The consumption of dairy products in pregnancy is widely extended. However, whether the consumption of low or high fat dairy produce is more beneficial for maternofetal health has yet to be established. Research design and methods This prospective cohort study evaluated the effect of consumption of dairy products during pregnancy on the frequency of gestational diabetes mellitus (GDM) and a composite of adverse maternofetal outcomes (CMF0). Pregnant women receiving obstetric care between 2014 and 2017 were eligible. Those who consumed $\geq 3$ servings/day of dairy products at 24-28 gestational weeks (GWs) were included and analyzed $(n=2004)$. The population was stratified into three groups according to intake of fat-free dairy productsskimmed milk and fat-free yoghurt and cheese-(days/ week): infrequent (1-2), average (3-6) and regular (7). Logistic regression analysis compared ORs $(95 \% \mathrm{Cl})$ for GDM and CMFO between the three groups (where the group of reference was the 'infrequent' intake group). Results After adjusting for confounding factors, no significant associations were found between the degree of consumption of fat-free dairy products and the risk of GDM and a CMF0. Moreover, when categorized by the degree of adherence to the Mediterranean diet (above or below the median score), associations were found between the 'regular' intake group and an increased risk of having a CMFO in women with a high adherence to the Mediterranean diet (OR: 1.50; 95\% Cl: 1.01 to 2.22; $\mathrm{p}<0.05)$. Weight gain during pregnancy did not differ among groups.

Conclusions The consumption of fat-free dairy products during pregnancy does not seem to be beneficial for maternofetal health.

\section{INTRODUCTION}

The optimal nutrition for pregnant women has not been completely defined. Adherence to a Mediterranean diet (MedDiet) in pregnancy seems to promote the health of the mother and her newborn. It has been associated with a lower incidence of gestational diabetes mellitus (GDM) and of other adverse

\section{Significance of this study}

What is already known about this subject?

- In Spain, current pregnancy dietary guidelines are based on Mediterranean diet principles, and recommend a daily consumption of dairy products.

- In order to control gestational weight gain, fat-free dairy products are recommended instead of full-fat dairy.

- The impact of consumption of fat-free over full-fat dairy on adverse maternofetal events has yet to be elucidated.

What are the new findings?

- A regular consumption of fat-free dairy products in pregnancy is not associated with a lower risk of gestational diabetes mellitus or an improvement in overall adverse maternofetal events.

How might these results change the focus of research or clinical practice?

- We found no evidence suggesting that having a higher consumption of fat-free dairy products is better for maternofetal health.

- Furthermore, their intake seems to have a neutral effect on gestational weight gain.

- Therefore, the current recommendations for pregnant women to consume fat-free dairy products in the context of a Mediterranean diet should be re-considered.

pregnancy outcomes associated with both obesity and GDM. ${ }^{1-6}$ Moreover, the adherence to six food targets based on the MedDiet is accompanied by a reduction in adverse events during pregnancy. ${ }^{7}$

The intake of milk and dairy products has been associated with an improved metabolic profile, lower rates of obesity, metabolic syndrome (MetS) and hypertension. However, the consumption of dairy products 
has not been found to reduce the rate of type 2 diabetes in our population. ${ }^{8}$

In pregnancy, calcium requirements are markedly increased, and consumption of dairy products is the norm. Dietary guidelines for pregnancy recommend the consumption of at least three servings/day of dairy products, in any of its forms. ${ }^{9}$ Most pregnant women comply with this recommendation. ${ }^{10}$ In addition, adequate gestational weight gain and a reduction in the intake of saturated fatty acids are important in pregnancy. Therefore, the intake of fat-free dairy products has been recommended. In our population, $<50 \%$ of women consume fatfree dairy products and $<26 \%$ fortified dairy products. ${ }^{11}$

In a previous study, we found no association between fat-free dairy products and the diagnosis of GDMregardless of whether GDM diagnosis had been made following Carpenter-Coustan or the International Association of Diabetes and Pregnancy Study Groups (IADPSG) criteria. ${ }^{9}$ Moreover, results regarding the association of fat-free dairy consumption with metabolic diseases are inconsistent. In fact, recent research suggests that full-fat dairy foods are more beneficial for the prevention of cardiometabolic diseases. ${ }^{12-15}$

Since 2014, the diet of pregnant women in our area of influence is based on MedDiet principles. Guidelines include a recommendation for consumption of at least three servings/day of dairy products, preferably fat-free or low-fat.

The aim of this study is to evaluate whether a high versus a low intake of fat-free dairy products-skimmed milk and fat-free yoghurt and cheese-improves the health of pregnancy, as determined by the rate adverse maternal, delivery and newborn outcomes. We hypothesize that a high consumption is beneficial for maternofetal health.

\section{RESEARCH DESIGN AND METHODS}

\section{Study design}

This is a prospective study using the St. Carlos pregnancy database. It includes women receiving medical care between 2014 and 2017. Part of this cohort of women has been used in two previously published studies. ${ }^{16}$ For the present study, the sample was treated as a cohort and all women were clustered into the same group.

Briefly, these studies sought to evaluate whether an early nutritional intervention, based on MedDiet principles, can reduce the incidence of GDM in women with normal glucose tolerance $(<92 \mathrm{mg} / \mathrm{dL})$ at the first gestational visit (8-12 gestational weeks (GWs)). Regardless of whether women had been randomized to a control or intervention group, all had been recommended $\geq 3$ servings/day of dairy products (preferably fat-free to help control gestational weight gain).

All women signed a letter of informed consent.

\section{Study population}

All pregnant women who attended the first gestational visit at 8-12 GWs and had a normal fasting serum glucose level $(<92 \mathrm{mg} / \mathrm{dL})$ were invited to participate in this study. Participants received an early dietary intervention based on MedDiet guidelines, with emphasis on the importance of consuming daily at least $40 \mathrm{~mL}$ of extra virgin olive oil and a handful of nuts. All women were recommended $\geq 3$ servings/day of dairy products-preferably skimmed milk, and fat-free yogurt and cheese.

All participants attended the same number of gestational visits 1 (8-12 GWs) and 2 (24-28 GWs). Prepregnancy dietary habits were referred to retrospectively and recorded at visit 1 . Dietary habits during pregnancy-between 8-12 and 24-28 GWs-were recorded at visit 2.

Women who consumed $\geq 3$ servings / day of dairy products in pregnancy (irrespective of the fat content) were included in this study. These women were then stratified into three groups according to their weekly consumption of fat-free dairy products during pregnancy. Dairy products included milk, cheese, yoghurts and any other dairy desserts or dairy-based products. These groups were labeled as 'regular', 'average' and 'infrequent'. Daily dairy intake was considered 'regular', whereas dairy intake 3-6 days a week was considered 'normal'. Dairy intake 1-2 days a week was labeled 'infrequent'.

\section{Lifestyle assessment}

Two questionnaires were used to evaluate the dietary habits of the women. The 14-item Mediterranean Diet Adherence Screener (MEDAS) was used to evaluate adherence to the MedDiet. It is based on 14 food items and was used to determine the 'MEDAS score'. A detailed description of the evaluation method is described elsewhere. In this questionnaire, only one item evaluates minimally the consumption of dairy products, in the form of creams, margarine and butter. The intake of $<1$ serving/day is considered to be favorable. ${ }^{17}$

The Diabetes Nutrition and Complications Trial questionnaire was used to evaluate whether lifestyle was healthy as well as eating habits. It consists of 15 items, 12 food items and 3 items related to physical activity. This was used to obtain the 'Nutrition Score'. It was also used to evaluate the consumption of individual food groups. All dairy products-cheese, yoghurts and milk-were evaluated as a single food group. However, consumption of fat-free, low-fat and full-fat dairy products were evaluated separately. In addition, the intake of butter, creams, margarine and fortified dairy products was registered. All data were recorded according to frequency of consumption (days/week), regardless of how many servings/day were eaten.

\section{Outcome measures}

The primary outcome of this study was to evaluate the effect of different degrees of consumption of fat-free dairy products in pregnancy on the risk of GDM and on a composite of adverse maternofetal outcomes. 


\section{Outcomes}

The following maternal, delivery and neonatal outcomes were assessed:

- Maternal: GDM (diagnosed according to IADPSG criteria), pregnancy-induced hypertension $(\geq 140 \mathrm{~mm}$ $\mathrm{Hg}$ systolic blood pressure (sBP) and/or $\geq 90 \mathrm{~mm} \mathrm{Hg}$ diastolic blood pressure (dBP) after $20 \mathrm{GWs}$ ), preeclampsia ( $\geq 140 \mathrm{~mm} \mathrm{Hg} \mathrm{sBP}$ and/or $\geq 90 \mathrm{~mm} \mathrm{Hg} \mathrm{dBP}$ with proteinuria $\geq 300 \mathrm{mg}$ in 24 hours after $20 \mathrm{GWs}$ ), prematurity (<37 GWs), urinary tract infections (number of events requiring antibiotic treatment) and cholestasis.

- Delivery: caesarean delivery, shoulder dystocia and perineal trauma.

- Neonatal: birth weight and height, large-forgestational-age (>90th percentile), small-forgestational-age ( $<10$ th percentile), cord blood $\mathrm{pH}<7$, Apgar score $<5$, neonatal hypoglycemia (suspicion of hypoglycemia, confirmed by a glycemia of $<35 \mathrm{mg} /$ dL), hyperbilirubinemia (suspicion of hyperbilirubinemia, confirmed by serum bilirubin $>18 \mathrm{mg} / \mathrm{dL}$ ), respiratory distress and admission to a neonatal intensive care unit (NICU).

With this set of data, four models of a composite of adverse outcomes were evaluated:

- Composite of maternal outcomes. Having $\geq 1$ event: prematurity, pre-eclampsia, albuminuria, urinary tract infection, cholestasis and GDM.

- Composite delivery outcomes. Having $\geq 1$ event: caesarean section, shoulder dystocia and perineal trauma.

- Composite of newborn outcomes. Having $\geq 1$ event: small-for-gestational age, large-for-gestational-age, pH of cord blood, Apgar score, hyperbilirubinemia, respiratory distress, hypoglycemia and admission in NICU.

- Composite of maternofetal outcomes. Having $\geq 1$ composite of adverse maternal, of delivery and of newborn outcomes.

\section{Statistical analysis}

Categorical variables were expressed as frequencies and relative frequencies $(\%)$, and continuous variables as means and SD.

For categorical variables, comparison between groups were evaluated by the $\chi^{2}$ test. For continuous variables, the comparison between two means were analyzed using Student's t-test.The non-parametric Mann-Whitney U test was used if the quantitative variables would not adjust to a normal distribution. For more than two means, the oneway analysis of variance test was applied. The ShapiroWilk test was used to verify the normal distribution of data. The ORs for each categorical variable and 95\% CIs were obtained from frequency tables. The group of reference was the 'infrequent' consumption group (1-2 days/week). Logistic binary regression analyses were performed to select the significant factors when variables were considered jointly in composite variables $(0$, no events and 1 at least one event) and were categorized by body mass index (BMI) $\left(<25\right.$ and $\left.\geq 25 \mathrm{~kg} / \mathrm{m}^{2}\right)$ and by MEDAS score (above or below the median). The median in pregnancy was of $\leq 6.6$ and $>6.6$. A multivariable final model was categorized to assess the effect of the degree of consumption of fat-free dairy products on the risk of GDM and on four models of composite adverse maternofetal outcomes.

Logistic regression analyses were used to assess the unadjusted and adjusted effect of the consumption fatfree dairy products on the risk for GDM and a composite of adverse maternofetal outcomes. ORs and its 95\% CIs were computed. The models were adjusted for age, ethnicity, family history of having of MetS, history of miscarriage, primiparity and level of education. Twotailed $\mathrm{p}$ values were calculated, with $\mathrm{p}<0.05$ indicating statistical significance. Analyses were performed using SPSS V.21 (SPSS, Chicago, Illinois, USA).

\section{RESULTS}

Of 2521 eligible women, $2004(79.5 \%)$ consumed $\geq 3$ servings/day of dairy products and, thus were included in the final analysis. This sample of women had an average age of $32.63 \pm 5.18$ years, BMI of $23.3 \pm 4.0 \mathrm{~kg} / \mathrm{m}^{2}$ and were predominantly of Caucasian origin (65.7\%). Moreover, $850(42.4 \%)$ were primiparous, $1310(66.4 \%)$ held a university degree, $842(42.1 \%)$ had a family history of having $>1$ component of MetS, 686 (34.2\%) had a history of miscarriage, and $156(7.8 \%)$ were current smokers.

The demographic and clinical data of the women as stratified according to the degree of consumption of fatfree dairy products during pregnancy is shown in table 1 .

A higher consumption of fat-free dairy products in pregnancy was associated with older age, a family history of MetS, primiparity and having a university degree (all $\mathrm{p}<0.05)$. It was also associated with higher nutrition and MEDAS scores (all $\mathrm{p}<0.05$ ). Moreover, weight gain during pregnancy (at 24-28 GWs and at 36-38 GWs) was not significantly different among groups.

Online supplementary table S1 shows the rates of adverse maternofetal outcomes, according to consumption of fat-free dairy products in pregnancy. The higher the consumption, the higher the rates of Cesarean delivery and the lower the rates of admission to NICU. No other significant results were observed.

Figure 1A,B show logistic regression analysis for the probability of having GDM and a CMFO according to the level of consumption of fat-free dairy products. This analysis was performed in crude, and categorized by BMI and MEDAS score.

When categorized by the adherence to the MedDiet (above or below the median score), no significant associations were found between the frequency of consumption of fat-free dairy products and the risk for GDM (online supplementary figure $1 \mathrm{Sa}$ ). However, both an average and regular intake were associated with an increased risk of having a composite of adverse maternofetal outcomes 
Table 1 Demographic characteristics and nutritional data of women, stratified by groups according to intake of fat-free dairy products in pregnancy

\begin{tabular}{|c|c|c|c|c|}
\hline & \multicolumn{3}{|l|}{ Groups } & \multirow[b]{2}{*}{$P$ value } \\
\hline & Infrequent & Average & Regular & \\
\hline $\mathbf{N}(\%)$ & 1103 & 146 & 755 & \\
\hline Age & $31.9 \pm 5.4$ & $33.4 \pm 5.0$ & $33.6 \pm 4.6$ & 0.001 \\
\hline \multicolumn{5}{|l|}{ Race/Ethnicity (\%) } \\
\hline Caucasian & $659(59.7)$ & $52(69.8)$ & $555(73.6)$ & \multirow[t]{2}{*}{0.001} \\
\hline Hispanic & $406(36.8)$ & $5(3.4)$ & $185(24.5)$ & \\
\hline Family history $>1$ component of MetS & $416(37.8)$ & $64(44.1)$ & $364(48.0)$ & 0.001 \\
\hline History of miscarriage & $383(34.7)$ & 49 (33.6) & $254(33.6)$ & 0.634 \\
\hline Primiparous & $431(39.2)$ & $65(44.8)$ & $353(46.9)$ & 0.043 \\
\hline Prepregnancy BW (kg) & $60.8 \pm 10.6$ & $64.4 \pm 12.4$ & $62.3 \pm 11.4$ & 0.001 \\
\hline Prepregnancy BMI $\left(\mathrm{kg} / \mathrm{m}^{2}\right)$ & $23.2 \pm 3.9$ & $24.4 \pm 4.7$ & $23.3 \pm 4.0$ & 0.004 \\
\hline BW at $24-28 \mathrm{GWs}(\mathrm{kg})$ & $62.7 \pm 11.0$ & $66.3 \pm 12.6$ & $64.6 \pm 11.5$ & \\
\hline Weight gain at $24-28 \mathrm{GWs}(\mathrm{kg})$ & $7.0 \pm 4.5$ & $7.1 \pm 4.1$ & $7.5 \pm 4.0$ & 0.067 \\
\hline BW at $36-38 \mathrm{GWs}(\mathrm{kg})$ & $73.1 \pm 10.8$ & $74.2 \pm 11.1$ & $74.3 \pm 12.1$ & 0.146 \\
\hline Weight gain at $36-38 \mathrm{GWs}(\mathrm{kg})$ & $12.1 \pm 6.2$ & $10.9 \pm 5.9$ & $11.9 \pm 6.4$ & 0.173 \\
\hline University degree & $647(58.7)$ & $102(69.8)$ & 568 (75.3) & 0.001 \\
\hline Employed & $835(75.7)$ & $117(80.1)$ & $619(82.0)$ & 0.199 \\
\hline \multicolumn{5}{|l|}{ Smoker } \\
\hline Never & $630(57.1)$ & $81(55.5)$ & $420(55.6)$ & \multirow[t]{2}{*}{0.917} \\
\hline Current & $88(8.0)$ & $11(7.5)$ & $57(7.5)$ & \\
\hline Prepregnancy MEDAS & $5.0 \pm 1.7$ & $5.2 \pm 1.6$ & $5.3 \pm 1.8$ & 0.002 \\
\hline Prepregnancy nutrition & $-0.4 \pm 3.0$ & $0.7 \pm 2.9$ & $1.4 \pm 3.1$ & 0.001 \\
\hline Pregnancy MEDAS score & $6.2 \pm 1.8$ & $6.6 \pm 1.9$ & $6.8 \pm 1.8$ & 0.001 \\
\hline Pregnancy nutrition score & $1.0 \pm 3.2$ & $2.9 \pm 3.0$ & $4.4 \pm 3.1$ & 0.001 \\
\hline \multicolumn{5}{|l|}{ Consumption of dairy (days/week) } \\
\hline Fat-free & $0.1 \pm 0.6$ & $3.8 \pm 1.0$ & $7.0 \pm 0.5$ & 0.001 \\
\hline Low-fat & $4.1 \pm 3.4$ & $4.7 \pm 3.3$ & $1.7 \pm 3.0$ & 0.001 \\
\hline Full-fat & $5.0 \pm 2.7$ & $3.4 \pm 2.7$ & $3.0 \pm 2.9$ & 0.001 \\
\hline Fortified & $1.5 \pm 2.8$ & $2.0 \pm 3.1$ & $2.3 \pm 3.3$ & 0.001 \\
\hline Butter/Desserts & $1.5 \pm 2.2$ & $1.3 \pm 2.1$ & $1.0 \pm 1.9$ & 0.001 \\
\hline
\end{tabular}

Data are mean \pm SD or number (\%). Regular: 7 days/week; average: 3-6 days/week; infrequent: 1-2 days/week.

$P$ value denotes differences between groups analyzed with $\chi^{2}$ test or analysis of variance.

BMI, body mass index; BW, body weight; GWs, gestational weeks; MEDAS, Mediterranean Diet Adherence Screener; MetS, metabolic syndrome.

in those above the median score (OR: 2.48; $95 \%$ CI: 1.08 to 5.70 and $1.50 ; 1.01$ to 2.22 , respectively, both $\mathrm{p}<0.05)$.

When adjusting for confounding factors, logistic regression analysis showed that the OR for a composite of adverse maternofetal outcomes was of 1.30 (95\% CI: 0.77 to $2.19 ; \mathrm{p}=0.328)$ for average intake and of $1.16(95 \% \mathrm{CI}$ : 0.88 to $1.54 ; \mathrm{p}=0.294$ ) for regular intake.

Online supplementary figure S1 shows logistic regression analysis assessing the effect of the degree of consumption of fat-free dairy products on the risk of a composite of adverse maternal, delivery and newborn outcomes. A regular intake of fat-free dairy was associated with a lower risk of having a composite of adverse maternal outcomes, categorized by BMI $\geq 25 \mathrm{~kg} / \mathrm{m}^{2}$ (online supplementary figure $1 \mathrm{Sa}$ ). Moreover, an average intake was associated with the risk of having a composite of adverse delivery outcomes categorized by MEDAS score $\leq 6.6$.

\section{DISCUSSION}

This prospective study shows that the consumption of fatfree dairy products is not associated with maternofetal health benefits. In fact, the results indicate that women who had an average and regular intake of fat-free dairy products had more adverse maternofetal outcomes than those who rarely consumed them. To our knowledge, 
A Gestational diabetes mellitus.

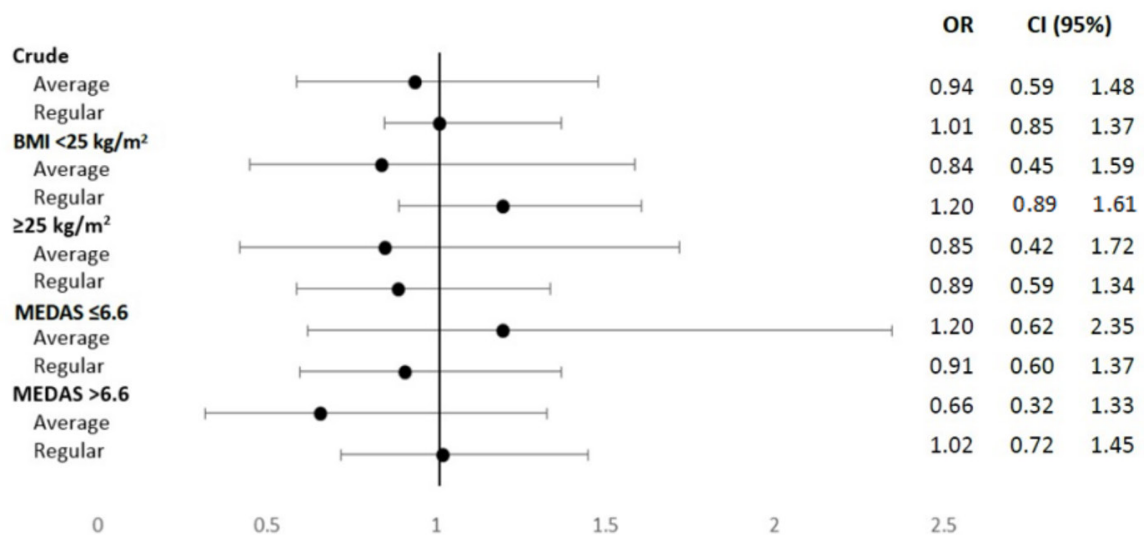

B Composite of maternofetal outcomes.

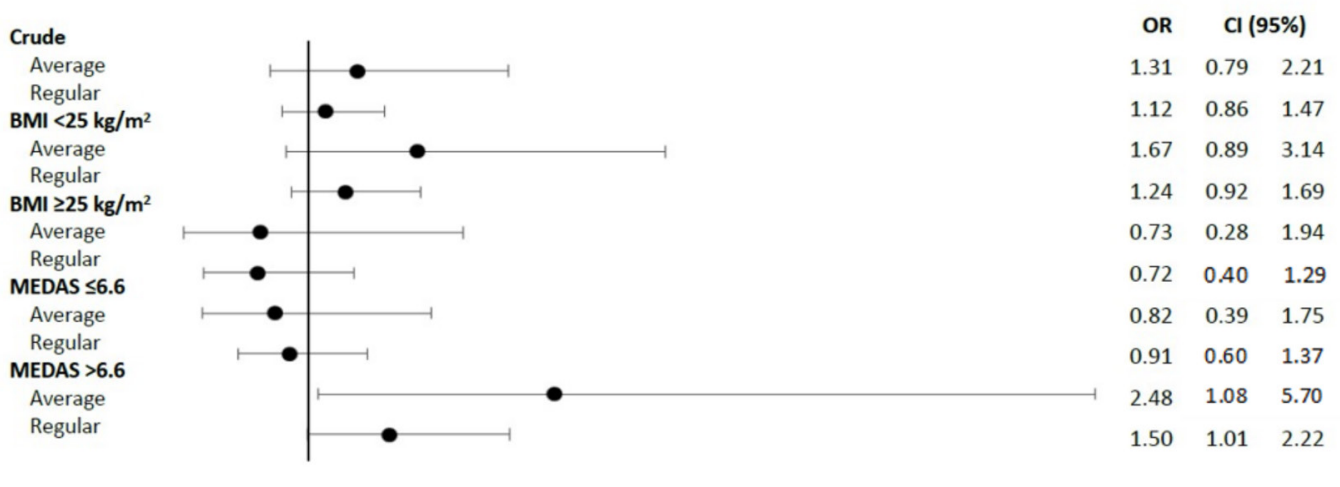

0

1

2

3

4

6

Figure 1 OR of having (A) gestational diabetes mellitus and (B) a composite of adverse maternofetal outcomes, according to the level of consumption of fat-free dairy products in pregnancy. Logistic regression analysis comparing OR with the reference group (infrequent consumption, 1-2 days/week). Regular: 7 days/week; average: 3-6 days/week. BMI, body mass index;

MEDAS, Mediterranean Diet Adherence Screener.

this is the first study that has evaluated the impact of consuming fat-free dairy products on adverse maternofetal outcomes.

In our sample, no associations were found between the consumption of fat-free dairy foods and the risk for GDM. A recent study found that circulating fatty acid biomarkers from dairy foods were associated with a lower incidence of diabetes. ${ }^{12}{ }^{13}$ Similar results were observed in another study, where the consumption of full-fat versus low-fat dairy was associated with a lower incidence of diabetes. ${ }^{14}$ Therefore, consumption of full-fat rather than fat-free dairy products seems to play a role in the prevention of diabetes. Since GDM and type 2 diabetes mellitus share pathophysiological mechanisms, this evidence suggests that the consumption of full-fat dairy foods could also have a protective effect on the development of GDM.

The results of the present study indicated that the more frequent the consumption of fat-free dairy products during pregnancy, the higher the rates of caesarean section. In addition, women who had a higher intake of fat-free dairy ran a higher risk of having a composite of adverse maternofetal outcomes as compared with those who had an 'infrequent' intake. This was specifically observed when categorizing by a MEDAS score above the median, that is, in women who had a higher adherence to the MedDiet.

Current pregnancy guidelines recommend adherence to a MedDiet pattern and the consumption of fatfree dairy products. Thus, it is not surprising to observe that women who have a high adherence to the MedDiet also have a higher consumption of the latter. Moreover, results showed that a higher consumption of fat-free dairy products is associated with older women and the higher the education level. Both older age and a high education level are usually associated with a higher degree of compliance with dietary recommendations and an overall better quality of diet. This is in line with previous results.

There is a lack of scientific evidence regarding the association of dairy food consumption in pregnancy with maternofetal health. Furthermore, there is little to no evidence on the implications of consuming either fat-free or full-fat dairy products for adverse outcomes. A single prospective cohort study of Norway has evaluated the consumption of probiotic milk on pregnancy outcomes, finding associations with a lower risk of pre-eclampsia. ${ }^{18}$ 
However, these results are probably linked to the effect of the probiotic rather than the milk per se.

A recent systematic review and meta-analysis evaluated the effect of milk and dairy consumption on adverse maternofetal outcomes. It reported that, due to the dearth of available studies, no conclusions can be drawn as concerns premature deliveries. However, there seem to be trends in the association of maternal milk intake with fetal weight and health. ${ }^{10}$ Moreover, in a prospective cohort study performed in a sample of Spanish women, the consumption of dairy products in the first half of pregnancy was linked to a lower risk of small-forgestational-age newborns. ${ }^{19}$ Similar results were observed in another prospective cohort study, where the consumption of dairy protein seemed to exert favorable effects on the newborns' birth weight, and was associated with a lower risk of low birth weight. ${ }^{20}$ However, there is no information on the effect of dairy intake on other adverse maternofetal outcomes. ${ }^{1019-23}$

Whether fat from milk and dairy products can be harmful, because of its high content in saturated fatty acids, is controversial. However, recent studies have found that the intake of full-fat dairy products has either a neutral or a beneficial effect on weight and cardiometabolic diseases. ${ }^{15}$ Furthermore, no studies in humans have found better health outcomes in persons consuming fat-free/low-fat dairy products as compared with those consuming full-fat dairy foods. In fact, a body of evidence suggests rather the opposite. ${ }^{12-15}$ However, the inconsistencies in the evidence make it difficult to recommend full-fat over low-fat dairy foods or vice versa. Similarly, we have found that the consumption of fat-free dairy products showed no benefit on gestational weight. This finding would question current recommendations of fatfree dairy products during pregnancy.

Currently, dietary guidelines for the general population as well as those specifically targeting pregnant women recommend the consumption of fat-free dairy products. They focus more on fat modification rather than the type of dairy (milk, yoghurt or cheese). However, evidence indicates that the impact on overall health differs depending on which type of dairy food is consumed.$^{24}$ The intake of low-fat or full-fat dairy has not been strongly associated with beneficial or harmful effects. However, fermented dairy products have been associated with improved cardiovascular health, and reduced risk of onset of type 2 diabetes. ${ }^{25-27}$ Moreover, results from the National Heart, Lung and Blood Institute's Framingham Heart Study Offspring Cohort revealed that cheese intake was associated with a dose-response inverse association with incident type 2 diabetes. ${ }^{28}$ Therefore, evidence suggests that the beneficial effects of consuming dairy produce could be more associated with food type (fermented dairy produce such as yoghurt and cheese) rather than fat modification (fat-free or full-fat).

An important limitation of this study is the fact that the stratification into different degrees of consumption of fatfree dairy products was done despite the possibility of a parallel intake of other dairy products with a different fat content (low-fat or full-fat). This means that it could be possible for some women to be consuming both low-fat and full-fat dairy products. Another limitation is that in the questionnaire used, milk, cheese and yoghurts were all grouped in the same food group of 'dairy products'. Therefore, it was not possible to differentiate between different dairy food types. This is important given that intake of yoghurts with probiotics and fermented dairy products such as cheese have been associated with improved health outcomes.

\section{CONCLUSIONS}

The consumption of fat-free dairy products is not associated with maternofetal health benefits. More studies need to be conducted to evaluate the effect on pregnancy outcomes of fat-free versus full-fat dairy produce consumption. Furthermore, future studies should be designed to distinguish the potential independent effects of specific dairy foods on maternal and fetal health.

\section{Author affiliations}

${ }^{1}$ Endocrinologia y Nutricion, Hospital Clínico Universitario San Carlos, Madrid, Spain ${ }^{2}$ Departamento de Medicina II, Facultad de Medicina, Universidad Complutense de Madrid, Madrid, Spain

${ }^{3}$ Instituto de Investigación Sanitaria del Hospital Clínico San Carlos (IdISSC), Centro de Investigación Biomédica en Red de Diabetes y Enfermedades Metabólicas Asociadas (CIBERDEM), Madrid, Spain

${ }^{4}$ Preventive Medicine Department, Hospital Clinico Universitario San Carlos, Madrid Spain

${ }^{5}$ Gynecology and Obstetrics Department, Hospital Clinico Universitario San Carlos, Madrid, Spain

${ }^{6}$ Endocrinologia y Nutricion, Medicina II, UCM, Hospital Clinico Universitario San Carlos, Madrid, Spain

Acknowledgements The authors would like to thank the administrative personnel, nurses and dietitians from the Laboratory Department (Marisol Sanchez Orta, María Dolores Hermoso Martín, María Victoria Saez de Parayuelo, Luzdivina Fernandez Muñoz and Félix Calzada) and the Pregnancy and Diabetes Unit (Amparo Sábate Garcia and Georgina Cutillas Dominguez).

Contributors CA-B and NGdIT contributed equally to this work. Conceptualization: CA-B, NGdIT, EB, AD, MAH, IR, VM, MC, MR and ALC-P, CA-B, NGdIT. Data curation: LdV, JV, IJ, MF, MAH, NI, IR, PdM, CF, MCM and AB. Formal analysis: CA-B, NGdIT, EB, IJ, AD, MF, PdM, AB, MR and ALC-P. Funding acquisition: CA-B, NGdIT and ALC-P. Investigation: LdV, JV, IJ, MAH, NI, IR, PdM, CF, MCM and AB. Methodology: LdV, JV, IJ, MAH, NI, IR, PdM, CF, MCM and AB. Supervision: MC, MR and ALC-P. Validation: ALC-P. Visualization: ALC-P. Writing — original draft: CA-B, NGdIT, AD and ALC-P. Writing review and editing: CA-B, NGdIT, AD, MR and ALC-P. All authors have seen and agreed with the content of the last version of the manuscript. ALC-P is the guarantor of this work and as such had full access to all the data in the study and takes responsibility for the integrity of the data and the accuracy of the data analysis.

Funding This research was funded by grants from Fundación para Estudios Endocrinometabolicos, IdISSC Hospital Clínico San Carlos, Universidad Complutense of Madrid, Medicine Department; the Instituto de Salud Carlos III of Spain under grant number PI17/01442; and Fondo Europeo de Desarrollo Regional (FEDER). The design and conduct of the study; collection, management, analysis and interpretation of the data; preparation, review and approval of the manuscript and decision to submit the manuscript for publication are the responsibilities of the authors alone and independent of the funders.

Competing interests None declared.

Patient consent for publication Not required.

Ethics approval The studies included in this analysis were approved by the Ethics Committee of Hospital Clínico San Carlos (ethic codes Cl 13/296-E and Cl 16/442-E) and conducted according to the Declaration of Helsinki. 
Provenance and peer review Not commissioned; externally peer reviewed.

Data availability statement All data relevant to the study are included in the article or uploaded as supplementary information. The database is available at a reasonable request to the corresponding author.

Open access This is an open access article distributed in accordance with the Creative Commons Attribution Non Commercial (CC BY-NC 4.0) license, which permits others to distribute, remix, adapt, build upon this work non-commercially, and license their derivative works on different terms, provided the original work is properly cited, appropriate credit is given, any changes made indicated, and the use is non-commercial. See: http://creativecommons.org/licenses/by-nc/4.0/.

ORCID iDs

Carla Assaf-Balut http://orcid.org/0000-0002-6217-3770

Alfonso Luis Calle-Pascual http://orcid.org/0000-0002-3628-9323

\section{REFERENCES}

1 Assaf-Balut C, García de la Torre N, Durán A, et al. A Mediterranean diet with additional extra virgin olive oil and pistachios reduces the incidence of gestational diabetes mellitus (GDM): a randomized controlled trial: the St. Carlos GDM prevention study. PLoS One 2017;12:e0185873.

2 Olmedo-Requena R, Gómez-Fernández J, Amezcua-Prieto C, et al. Pre-pregnancy adherence to the Mediterranean diet and gestational diabetes mellitus: a case-control study. Nutrients 2019;11:E1003.

3 H Al Wattar B, Dodds J, Placzek A, et al. Mediterranean-style diet in pregnant women with metabolic risk factors (Esteem): a pragmatic multicentre randomised trial. PLoS Med 2019;16:e1002857.

4 Schoenaker DA, Soedamah-Muthu SS, Mishra GD. Quantifying the mediating effect of body mass index on the relation between a Mediterranean diet and development of maternal pregnancy complications: the Australian longitudinal study on women's health. Am J Clin Nutr 2016;104:638-45.

5 Assaf-Balut C, Familiar C, García de la Torre N, et al. Gestational diabetes mellitus treatment reduces obesity-induced adverse pregnancy and neonatal outcomes: the St. Carlos gestational study. BMJ Open Diabetes Res Care 2016;4:e000314.

6 Assaf-Balut C, Garcia de la Torre N, Durán A, et al. Medical nutrition therapy for gestational diabetes mellitus based on Mediterranean diet principles: a subanalysis of the ST Carlos GDM prevention study. BMJ Open Diabetes Res Care 2018;6:e000550.

7 Assaf-Balut C, García de la Torre N, Fuentes M, et al. A high adherence to six food targets of the Mediterranean diet in the late first trimester is associated with a reduction in the risk of MaternoFoetal outcomes: the St. Carlos gestational diabetes mellitus prevention study. Nutrients 2019;11:E66.

8 Lago-Sampedro A, García-Escobar E, Rubio-Martín E, et al. Dairy Product Consumption and Metabolic Diseases in the Di@bet.es Study. Nutrients 2019;11:E262.

9 Ministry of health, social services and equality, Agency for healthcare technology assessment of Andalucia. Clinical practice guidelines for care in pregnancy and puerperium. AETSA, 2014.

10 Achón M, Ubeda N, García-González Ángela, et al. Effects of milk and dairy product consumption on pregnancy and lactation outcomes: a systematic review. Adv Nutr 2019;10:S74-87.

11 Ruiz-Gracia T, Duran A, Fuentes M, et al. Lifestyle patterns in early pregnancy linked to gestational diabetes mellitus diagnoses when using IADPSG criteria. The ST Carlos gestational study. Clin Nutr 2016;35:699-705.

12 Yakoob MY, Shi P, Willett WC, et al. Circulating biomarkers of dairy fat and risk of incident diabetes mellitus among men and women in the United States in two large prospective cohorts. Circulation 2016;133:1645-54.

13 Imamura F, Fretts A, Marklund M, et al. Fatty acid biomarkers of dairy fat consumption and incidence of type 2 diabetes: a pooled analysis of prospective cohort studies. PLoS Med 2018;15:e1002670.

14 Kummer K, Jensen PN, Kratz M, et al. Full-Fat dairy food intake is associated with a lower risk of incident diabetes among American Indians with low total dairy food intake. J Nutr 2019;149:1238-44.

15 Soedamah-Muthu SS, de Goede J, Consumption D. Dairy consumption and cardiometabolic diseases: systematic review and updated meta-analyses of prospective cohort studies. Curr Nutr Rep 2018;7:171-82.

16 de la Torre NG, Assaf-Balut C, Jiménez Varas I, et al. Effectiveness of following Mediterranean diet recommendations in the real world in the incidence of gestational diabetes mellitus (GDM) and adverse Maternal-Foetal outcomes: a prospective, universal, interventional study with a single group. The ST Carlos study. Nutrients 2019;11:E1210.

17 Schröder H, Fitó M, Estruch R, et al. A short screener is valid for assessing Mediterranean diet adherence among older Spanish men and women. J Nutr 2011;141:1140-5.

18 Nordqvist M, Jacobsson B, Brantsæter A-L, et al. Timing of probiotic milk consumption during pregnancy and effects on the incidence of preeclampsia and preterm delivery: a prospective observational cohort study in Norway. BMJ Open 2018;8:e018021.

19 Olmedo-Requena R, Amezcua-Prieto C, Luna-Del-Castillo JdeD, et al. Association between low dairy intake during pregnancy and risk of small-for-gestational-age infants. Matern Child Health J 2016:20:1296-304.

20 Heppe DHM, van Dam RM, Willemsen SP, et al. Maternal milk consumption, fetal growth, and the risks of neonatal complications: the generation R study. Am J Clin Nutr 2011:94:501-9.

21 Karimbeiki R, Derakhshandeh Rishehri SM, Kelishadi R, et al. Association of milk and dairy products consumption during pregnancy with fetal and neonatal head Circumferences: a systematic review. J Pediatr Rev. In Press 2016:e7690.

22 Brantsæter AL, Olafsdottir AS, Forsum E, et al. Does milk and dairy consumption during pregnancy influence fetal growth and infant birthweight? A systematic literature review. Food Nutr Res 2012;56:20050

23 Clark DC. Association of dairy protein intake during pregnancy with birth weight. Food Nutr Bull 2018;39:S54-9.

24 Mozaffarian D, Foods D. Dairy foods, obesity, and metabolic health: the role of the food matrix compared with single nutrients. Adv Nutr 2019:10:917S-23.

25 Díaz-López A, Bulló M, Martínez-González MA, et al. Dairy product consumption and risk of type 2 diabetes in an elderly Spanish Mediterranean population at high cardiovascular risk. Eur J Nutr 2016;55:349-60

26 Gijsbers L, Ding EL, Malik VS, et al. Consumption of dairy foods and diabetes incidence: a dose-response meta-analysis of observational studies. Am J Clin Nutr 2016;103:1111-24.

27 Lordan R, Tsoupras A, Mitra B, et al. Dairy fats and cardiovascular disease: do we really need to be concerned? Foods 2018;7:E29:29.

28 Hruby A, Ma J, Rogers G, et al. Associations of dairy intake with incident prediabetes or diabetes in middle-aged adults vary by both dairy type and glycemic status. J Nutr 2017;147:jn253401-1775. 